\title{
POLÍTICAS PÚBLICAS E FORMAS DE GESTÃO ESCOLAR: RELAÇÕES ESCOLA-ESTADO E ESCOLA- COMUNIDADE
}

\author{
Renata Maria Moschen Nascente (UFSCar)* \\ Celso Luiz Aparecido Conti (UFSCar)** \\ Emília Freitas de Lima (UFSCar)***
}

\begin{abstract}
RESUMO
$\mathrm{O}$ artigo analisa a visão de diretoras de escolas públicas de Ensino Fundamental do estado de São Paulo sobre políticas públicas e determinações legais de âmbito federal. Focaliza as relações escola-Estado e escola-comunidade, buscando identificar a predominância de elementos típicos de formas de gestão burocrática, gerencial e emancipatória. Advém de pesquisa qualitativa, realizada por meio de questionário aplicado a sessenta e cinco diretoras. Os resultados revelam que a forma burocrática continua vigorosa, principalmente quanto ao verticalismo das decisões, marcadamente nas relações escola-Estado, enquanto nas relações escola-comunidade se verificam traços gerencialistas. Há, assim, uma área de interseção entre os fortes princípios da burocracia e os fracos princípios do gerencialismo. Os princípios da forma emancipatória de gestão não se revelaram explicitamente nos dados, ainda que se admita que a presença da participação na forma gerencial possa constituir um germe da forma emancipatória.
\end{abstract}

Palavras-chave: Formas de gestão da escola. Relações escola-Estado. Relações escola-comunidade. Políticas públicas educacionais.

\begin{abstract}
PUBLIC POLICIES AND FORMS OF SCHOOL MANAGEMENT: SCHOOLSTATE AND SCHOOL-COMMUNITY RELATIONS

The article analyzes the view of public school directors of the State of São Paulo on public policies and legal determinations at the federal level. It focuses on school-state and school-community relations, in order to identify the predominance of typical elements of forms of bureaucratic, managerial and emancipatory management. It comes from qualitative research, carried out through a questionnaire applied to sixtyfive directors. The results show that the bureaucratic form remains vigorous, mainly regarding the verticalism of decisions, markedly in school-state relations, while in
\end{abstract}

* Doutora em Educação pela Universidade do Estado de São Paulo (Unesp - Rio Claro). Professora Adjunta da Universidade Federal de São Carlos (UFSCar). E-mail: rmmnascente@gmail.com

** Doutor em Educação pela Universidade de Campinas (Unicamp). Professor Associado da Universidade Federal de São Carlos (UFSCar). E-mail: celsocon@ufscar.br

*** Pós-doutora em Educação pela Pontifícia Universidade Católica do Rio de Janeiro (PUC-RJ). Doutora em Educação pela Universidade Federal de São Carlos (UFSCar). Professora Sênior da Universidade Federal de São Carlos (UFSCar). E-mail: eflima281001@gmail.com 
school-community relations there are managerial traits. There is, therefore, an area of intersection between the strong principles of bureaucracy and the weak principles of managerialism. The principles of the emancipatory form of management were not explicitly revealed in the data, although it is admitted that the presence of the participation in the managerial form can constitute a germ of the emancipatory form. Keywords: Forms of school management. School-State relations. School-community relations. Educational public policies.

\section{RESUMEN}

\section{POLÍTICAS PÚBLICAS Y FORMAS DE GESTIÓN ESCOLAR: RELACIONES ESCUELA-ESTADO Y ESCUELA-COMUNIDAD}

El artículo analiza la visión de directoras de escuelas públicas de Enseñanza Fundamental del estado de São Paulo sobre políticas públicas y determinaciones legales de ámbito federal. Se enfocan las relaciones escuela-Estado y escuelacomunidad, buscando identificar la predominancia de elementos típicos de formas de gestión burocrática, gerencial y emancipatoria. Adviene de investigación cualitativa, realizada por medio de un cuestionario aplicado a sesenta y cinco directoras. Los resultados revelan que la forma burocrática sigue siendo fuerte, principalmente en cuanto al verticalismo de las decisiones, marcadamente en las relaciones escuelaEstado, mientras que en las relaciones escuela-comunidad se verifican rasgos gerencialistas. Hay, así, un área de intersección entre los fuertes principios de la burocracia y los débiles principios del gerencialismo. Los principios de la forma emancipatoria de gestión no se revelaron explícitamente en los datos, aunque se admite que la presencia de la participación en la forma gerencial pueda constituir un germen de la forma emancipatoria.

Palabras clave: Formas de gestión de la escuela. Relaciones escuela-Estado. Relaciones escuela-comunidad. Políticas públicas educativas.

\section{Introdução}

$\mathrm{O}$ artigo analisa a visão de diretoras de escolas públicas de Ensino Fundamental do estado de São Paulo sobre políticas públicas e determinações legais de âmbito federal. Focaliza as relações escola-Estado e escola-comunidade, buscando identificar a predominância de elementos típicos de formas de gestão burocrática, gerencial e emancipatória. Constitui recorte de pesquisa qualitativa, realizada por meio de questionário aplicado a sessenta e cinco diretoras que em 2015 cursavam Especialização em Gestão Escolar na modalidade Educação a Distância, curso oferecido pela UFSCar em convênio com o Ministério da Educação (MEC).

$\mathrm{O}$ texto está estruturado em três partes. $\mathrm{Na}$ primeira são apresentadas e referenciadas teoricamente três formas de gestão: a burocrática, a gerencial e a emancipatória; na segunda são apresentados dados da pesquisa referentes às relações escola-Estado e escola-comunidade, analisados à luz do referencial teórico, procurando, assim, mostrar qual(is) formas de gestão predominam em cada uma dessas relações. Na terceira, a título de considerações finais, são sintetizadas as evidências possibilitadas pelas análises.

\section{Diferentes formas de gestão}

Nesta seção são apresentados elementos teóricos que caracterizam três formas de gestão, sendo o primeiro pautado na burocracia, o segundo na participação numa perspectiva gerencialista e o terceiro na participação mais democrática, emancipatória. 
A existência da burocracia remonta a tempos bastante longínquos, firmando-se cada vez mais, e de forma predominante, como regulação abstrata da prática da autoridade com o advento do Estado Moderno, em razão das exigências postas pela complexidade cada vez maior da civilização à administração pública e privada. Assim, de acordo com Weber (1991), a estrutura burocrática tem uma superioridade puramente técnica que justifica seu predomínio. Tal característica está diretamente relacionada a outra, igualmente importante: a de que "a administração burocrática tem, em geral, um caráter mais 'econômico' que outros tipos de administração” (WEBER, 1991, p. 53). Econômico, neste caso, está referido a eficiente.

A democracia de massas é uma das características da referida complexidade. Por passar a exigir igualdade perante a lei, em lugar dos privilégios e do tratamento caso a caso de questões administrativas, contribui para a instauração da burocracia em sua plenitude. E, uma vez instaurada, ela "constitui uma das estruturas sociais mais difíceis de destruir", estabelecendo-se como "uma forma de poder praticamente inamovível” (WEBER, 1991, p. 59).

A burocracia moderna tem caráter racional, e se sustenta, fundamentalmente, em dois princípios: o de setores jurisdicionais estáveis e oficiais e o de hierarquia de cargos e níveis de autoridade (WEBER, 1991).

O primeiro estabelece que: a) as atividades normais se dão de maneira estável e são entendidas como deveres oficiais; b) a autoridade que dá as ordens é distribuída de forma estável e rigorosamente delimitada por normas; c) os deveres e direitos correspondentes são regulados por um sistema de normas e, das pessoas que prestam os serviços, exige-se qualificação específica.

O segundo princípio - hierarquia de cargos e níveis de autoridade - refere-se a um sistema em que os funcionários superiores controlam os inferiores e os governados podem apelar a uma autoridade superior àquela a que se submeteram. Desse modo, "um alto desenvolvimento do tipo burocrático leva a uma organização monocrática da hierarquia de cargos" (WEBER, 1991, p. 10).

A posição do funcionário se configura como um dever, de modo que o acesso a um cargo implica a aceitação desse dever e a fidelidade a ele, confe- rindo ao funcionário existência segura e qualidade social. O funcionário faz parte de um mecanismo no qual realiza tarefas especializadas e é dirigido pelos que estão acima dele na hierarquia, não podendo iniciar nem parar esse mecanismo.

Apesar de sua vida longa, algumas características da administração burocrática vêm sendo questionadas, embora o modelo burocrático em geral não esteja inviabilizado historicamente, quer do ponto de vista teórico, quer do técnico.

O que se deve cogitar, portanto, não é a eliminação ou substituição da burocracia, mas a inserção de novos elementos, procedimentos e ideias no sistema nervoso central das estruturas burocráticas, de modo a dinamizá-las, democratizá-las e domesticá-las. (NOGUEIRA, 2011, p. 153).

Alguns desses elementos atingem o coração do modelo burocrático, como é o caso da participação, da cidadania e da sociedade civil (DAGNINO, 2004), cujas acepções variam de acordo com o projeto do qual fazem parte, ou seja, de acordo com o conjunto de "crenças, interesses, concepções de mundo, representações do que deve ser a vida em sociedade, que orientam a ação política dos diferentes sujeitos [...]" (DAGNINO, 2004, p. 144). Assim entendido, esse conceito de projeto pauta-se no estabelecimento de um vínculo indissolúvel entre a cultura e a política.

A autora refere-se a dois projetos distintos, sendo um voltado ao alargamento da democracia e outro ao ajuste neoliberal. O primeiro, cujo marco legal é a Constituição de 1988 (BRASIL, 1988), caracteriza-se pela criação de espaços públicos e pela participação da sociedade civil, engendrados no projeto democratizante e participativo dos anos 1980, na luta contra o regime militar. Dagnino (2004) menciona dois importantes marcos no percurso desse projeto. O primeiro diz respeito ao restabelecimento da democracia formal, com eleições livres e reorganização partidária, dando lugar ao trânsito da sociedade civil para o Estado. O segundo marco é a aposta na possibilidade de ação conjunta Estado-sociedade civil.

Essa aposta deve ser entendida num contexto no qual o princípio de participação da sociedade se tornou central como característica distintiva desse projeto, subjacente ao próprio esforço de criação de 
espaços públicos onde o poder do Estado pudesse ser compartilhado com a sociedade. (DAGNINO, 2004, p.141-142).

O segundo projeto - ajuste neoliberal - inicia-se em 1990, com a posse de Collor de Mello, instaurando novas relações entre Estado e sociedade civil, na qual aquele transfere para esta sua responsabilidade social, isentando-se da promoção da garantia de direitos.

Nesses projetos estão presentes, como referências comuns, os três elementos citados: participação, cidadania e sociedade civil. No entanto, há uma disputa de seus significados, produzindo o que Dagnino (2004) chama de "confluência perversa". Por perversa ela entende "um fenômeno cujas consequências contrariam sua aparência, cujos efeitos não são imediatamente evidentes e se revelam distintos do que se poderia esperar" (DAGNINO, 2004, p. 142). A confluência perversa determina um obscurecimento das distinções e divergências por meio de um vocabulário comum, de procedimentos e mecanismos institucionais marcados por fortes similaridades de significados.

A seguir explicitamos a visão dessa autora sobre o significado atribuído a cada um desses elementos.

A sociedade civil, no projeto neoliberal, bastante influenciado pelas agências internacionais, passa a ser identificada com o terceiro setor, composto por ONGs e fundações empresariais, marginalizando os movimentos sociais que contestam esse projeto. De acordo com a autora, as relações entre Estado e ONGs exemplificam a confluência perversa a que ela se refere. Isso porque:

Dotadas de competência técnica e inserção social, interlocutores 'confiáveis' entre os vários possíveis interlocutores na sociedade civil, elas são freqüentemente vistas como os parceiros ideais pelos setores do Estado empenhados na transferência de suas responsabilidades para o âmbito da sociedade civil. (DAGNINO, 2004, p. 149, grifo do autor).

Dagnino (2004) explica, ainda, que por meio das ONGs, determinados segmentos e causas sociais são representados junto ao Estado, o que particulariza objetivos, criando competitividade entre essas organizações, que não se unem em torno de demandas mais abrangentes. Portanto, essas organizações buscam o alargamento de suas representatividades, o que para elas significa ganhos no espaço político e econômico, potencializados, mormente, pelas diversas mídias e redes sociais.

A participação, princípio fundante do projeto democratizante, segue a mesma linha de deslocamento no projeto neoliberal pelo qual tem passado a sociedade civil. Segundo Dagnino (2004, p. 151), há "[...] a emergência da chamada 'participação solidária', e a ênfase no trabalho voluntário e na 'responsabilidade social', tanto de indivíduos como de empresas". Prevalecem nessa acepção de participação visões privatistas e individualistas, que obstaculizam o componente coletivo da participação democrática. Nesse sentido, a própria solidariedade é desconfigurada, passando a significar ações de valor moral no campo do privado. Assim, o potencial democrático da participação é esmaecido pela individualização no tratamento de problemas sociais. Fortalece-se o conformismo embebido na premissa de que se não é possível solucionar o problema para todos, cada um deve fazer sua parte para amenizar os males que afligem a sociedade. Nessa perspectiva, participar não diz respeito às tomadas de decisão, mas à partilha na implementação de políticas públicas com os setores privados. Justamente neste aspecto, entendemos que recai o esvaziamento do potencial democrático da participação, que por parte da sociedade civil passa a ter muito mais o sentido de colaborar do que de construir.

Seguindo essa linha de pensamento, de acordo com Dagnino (2004), a participação é redefinida no projeto neoliberal em um espectro gerencialista, no qual a administração privada sobrepõe-se à estatal, o que a despolitiza, portanto, afastando-a de sua acepção democrática, demarcada pela partilha de poder e pela deliberação.

Para Dagnino (1994), a cidadania no projeto democratizante começou a ser gestada no final dos anos de 1970 e durante a década de 1980, período no qual a sociedade brasileira foi gradativamente se organizando para demandar acesso a diversos equipamentos urbanos e lutar contra discriminações relativas às questões de gênero e etnia. Imbuída dos direitos humanos e animada pela resistência à ditadura, a chamada nova cidadania, ou cidadania ampliada, seria propiciadora de transformações sociais. A cidadania, assim, representava uma 
proposta de profunda mudança cultural na busca da democratização da sociedade, que não se restringiria mais à relação do indivíduo com o Estado, mas deveria ser urdida na e para a sociedade, propiciando uma nova sociabilidade, mais igualitária, estabelecendo novas regras de convivência. Portanto, a cidadania ampliada seria a:

[...] constituição de uma dimensão pública da sociedade, em que os direitos possam se consolidar como parâmetros públicos para a interlocução, o debate e a negociação de conflitos, tornando possível a reconfiguração de uma dimensão ética da vida social. (DAGNINO, 1994, p. 154).

Justamente esse potencial transformador que a cidadania adquiriu no Brasil é que vem sendo atacado pelo projeto neoliberal. Em primeiro plano, observa-se uma regressão da cidadania, que volta a significar a relação de cada indivíduo com o Estado. Em segundo, “[...] se estabelece uma sedutora conexão entre cidadania e mercado. Tornar-se cidadão passa a significar a integração individual ao mercado, como consumidor e como produtor" (DAGNINO, 1994, p. 155).

O conjunto de direitos adquiridos ao longo da última metade do século XX passa a ser entendido como obstáculo ao avanço econômico e social. Inverte-se a lógica da cidadania no projeto democrático, na qual os direitos conquistados eram vistos como sinais de avanço. No projeto neoliberal eles são percebidos como característica de uma sociedade anacrônica. Nesse sentido, a ideia de cidadania fica subsumida à de mercado, e, como acontece com a de participação, ela passa a ser identificada por ações individuais, de caráter filantrópico. Ser cidadão é ajudar os que precisam, participar é se organizar para isso. Aqueles que precisam não são vistos como cidadãos, mas como os carentes, que devem ser atendidos tanto por políticas públicas como por ações filantrópicas, tendo a iniciativa privada, com seu empreendedorismo, como formuladora tanto de umas como de outras. Dessa forma, em nome da eficiência e da eficácia, o privatismo impera nas relações sociais.

[...] o projeto neoliberal operaria não apenas com uma concepção de Estado mínimo, mas também com uma concepção minimalista tanto da política como da democracia. Minimalista, porque restringe não apenas o espaço, a arena da política, mas seus participantes, processos, agenda e campo de ação. (DAGNINO, 1994, p. 159).

Tendo em vista que a participação é considerada central num e noutro projeto, Nogueira (2011) explicita como a gestão pública passa por uma reconfiguração, tornando-se participativa, movimentando-se entre dois polos - democracia e neoliberalismo -, adquirindo no decorrer dessa movimentação diferentes características. Em razão dessa imbricação em diferentes níveis, têm diferido as práticas participativas nos diversos aparatos estatais, assim como no estabelecimento de políticas públicas.

Isso ocorre porque, de acordo com Nogueira (2011, p. 146), a participação, assume acepções diversas em razão de "ingredientes variados e múltiplos focos de ação, que vão do Estado ao mercado e à sociedade civil, do particular ao geral, da ética ao interesse". Assim, "a luta pela participação é também uma luta pelo seu conceito" (NOGUEIRA, 2011, p. 157).

Em uma perspectiva mais gerencial, a participação implica a "ideia de política como 'troca' entre governantes e governados" consubstanciada num "conjunto de práticas e de ações" com vista ao "sucesso eleitoral, à legitimação dos governantes e ao favorecimento a grupos sociais envolvidos" (NOGUEIRA, 2011, p. 146).

Ainda que, de acordo com o referido autor, essa participação gerencial contenha importantes elementos potenciais de democratização, ela pode ser "administrada", de modo a evitar a produção de efeitos incômodos e a participação efetiva das pessoas em escolhas essenciais, convertendo-se em recurso gerencial para solucionar determinados problemas. Desse modo, “[...] há gestores que usam a participação para dela se beneficiar e gestores que vivem a participação como um veículo de emancipação" (NOGUEIRA, 2011, p. 148, grifo do autor).

Por conseguinte, com base em Nogueira (2011), entendemos que a gestão participativa tem se configurado de diversas maneiras. Uma delas é uma nova articulação entre governantes e governados, de modo que o cidadão penetra na órbita do governo, interagindo com os gestores públicos. Essa interação é marcada pela negociação 
constante e contínua. A autonomia dos aparatos governamentais torna-se relativa, levando-os ao "estabelecimento de uma relação realista com os distintos elementos da economia global e de vínculos estreitos com os distintos setores sociais" (NOGUEIRA, 2011, p. 150).

Há também a introdução de novas formas de controle social, que tornam a gestão pública mais democrática e republicana. Os cidadãos passam a interferir na gestão, direcionando-a, e fazendo com que os gestores públicos passem a ser submetidos a sistemas de responsabilização, tanto na guarda de bens, como na segurança dos atendidos e nos serviços públicos prestados. Essa tendência tem possibilitado a transferência de poderes a conselhos e assembleias, que propiciam a democratização da administração pública.

Parcerias e descentralização também fazem parte da gestão participativa, mas de modo algum isentam o Estado de suas responsabilidades, e, menos ainda, passam à iniciativa privada e/ou terceiro setor a prerrogativa da oferta bens e serviços públicos. Se assim ocorrer, a gestão participativa estará servindo aos objetivos do projeto neoliberal, convertendo-se os "direitos de cidadania [...] em serviços a serem providos (e vendidos) pelo mercado ou pelo setor público não estatal" (NOGUEIRA, 2011, p. 151). Desse modo, as parcerias não devem ser entendidas como veículos que reconfigurariam políticas públicas, agilizando suas implementações, fora da esfera política. Por outro lado, para o autor, as parcerias não devem ser extintas do cenário dos serviços públicos, mas podem ser realizadas como instrumentos adequados em contextos de escassez de recursos, fragmentação social e de diversificação/ampliação de demandas. O fundamental é que o controle dos serviços ofertados seja público; que, por meio da gestão participativa deve "[...] dirigir, coordenar e impulsionar o processo de formulação, implementação e avaliação de políticas, tanto quanto para garantir a qualidade dos serviços públicos" (NOGUEIRA, 2011, p. 151).

A gestão participativa deve, dentro dos parâmetros da democracia, contar com a iniciativa e a criatividade dos coletivos, possibilitando a transformação social, por meio do combate às desigualdades e da promoção da inclusão e da seguridade social. Assim, seus objetivos estão voltados muito mais ao bem-estar da população do que aos custos e lógicas operacionais para alcançá-los. Isso não significa que organização e administração não sejam fundamentais na gestão participativa democrática, ao contrário, "[...] a entrada em cena da participação exige alterações substanciais na forma de dirigir as organizações públicas, de gerenciar seus recursos e procedimentos, de organizá-las" (NOGUEIRA, 2011, p. 152).

Nesse aspecto, consideramos que as novas formas de administrar e organizar os aparatos governamentais não podem ser planejadas e executadas segundo o reformismo neoliberal, mas devem ter como foco a construção social com base na formação de pessoal e em alterações nas culturas organizacionais. A gestão participativa democrática reúne técnica, política, criatividade e iniciativa para alcançar a agilização da burocracia, que não deve ser eliminada, mas modernizada, tornando-a flexível o suficiente para planejar democraticamente, atuando de modo descentralizado e de estímulo à cooperação. Compreende-se, assim, que desburocratizar não significa eliminar a burocracia e muito menos introduzir procedimentos competitivos, gerenciais, tecnológicos e empreendedores para agilizar os órgãos prestadores de serviços públicos, mas construir uma burocracia arejada, crítica, aberta a mudanças, a serviço dos cidadãos.

$\mathrm{Na}$ gestão participativa democrática, o planejamento é dinâmico, baseado em planos que são apostas, explicitações de objetivos e ações elaboradas coletivamente. Os planos podem ser entendidos como parâmetros e sinalizações que dão pistas aos agentes públicos de como agir e proceder no cotidiano de suas relações sociais. Essa viabilização de planos é que constitui o planejamento democrático.

Portanto, a gestão e o planejamento democráticos e participativos exigem novos gestores que devem ser "bons intelectuais", mais do que "bons burocratas", precisando aliar: “[...] especialização técnico-administrativa com protagonismo ético-político. Somente assim têm condições de exercer liderança efetiva e de lidar com a participação não como recurso de legitimação governamental, mas como espaço de emancipação" (NOGUEIRA, 2011, p. 155).

Assim, na perspectiva aqui defendida, a participação - emancipatória - caracteriza-se funda- 
mentalmente pela possibilidade de interferência efetiva nas decisões, na execução, na avaliação e no controle, quer de forma direta, quer pelas vias representativas, mobilizando politicamente a sociedade civil, produzindo efeitos ético-políticos superiores. Tais efeitos estão associados à participação voltada para a conquista de um direito ou ao atendimento de uma demanda que se mostre aberta aos outros, rompendo com a subalternidade e com a manipulação. Isso significa comprometer-se com a democratização. Em outros termos, pode-se falar em uma participação efetiva, capaz de "civilizar a burocracia” (NOGUEIRA, 2011, p. 154).

\section{Relações entre escola-Estado e escola-comunidade}

Nesta seção são apresentados os dados da pesquisa que trazem indícios de como se dão as relações da escola com as instâncias enunciadas, ao tempo em que eles são analisados com base nas categorias adotadas no referencial teórico: formas de gestão burocrática, gerencial e emancipatória.

\subsection{Relações escola-Estado}

Quanto às relações escola-Estado, os resultados da pesquisa indicam a predominância de uma visão positiva das políticas e normativas por parte das diretoras. Isso pode ser percebido quando se analisa, por exemplo, a visão delas quanto ao Programa Dinheiro Direto na Escola (PDDE), ao Projeto Político-Pedagógico (PPP), à Base Nacional Comum Curricular (BNCC) e às Avaliações Externas.

No que concerne ao PDDE, a visão positiva em relação a essa política se justifica, segundo as diretoras, pela liberdade e autonomia no uso dos recursos financeiros. Houve unanimidade quanto ao efeito positivo desse Programa sobre a infraestrutura pedagógica, mormente no que se refere à possibilidade de aquisição de materiais pedagógicos - livros, brinquedos, jogos, materiais escolares - e equipamentos - computador, impressora, rádio e data show. Algumas respostas ilustram essa afirmação:

Podemos investir na parte física para pequenas melhorias, como instalação de aparelhos multimídia em altura segura para alunos; troca de pequenas estruturas, como maçanetas, lâmpadas, tomadas, entre outros; compra de recursos para o bem-estar das crianças, como cortinas e ventiladores. (P24).

De acordo com o PPP da escola, o PDDE auxilia em aquisição de materiais permanentes e de consumo. No nosso caso, tudo é pensado na melhoria da aprendizagem dos alunos. Exemplo: confecção de banners para as salas de aula, aquisição de jogos educativos, materiais para projeto da escola etc. (P35).

Ainda quanto ao PDDE, foram consideradas a liberdade e a autonomia nos planos financeiro, administrativo, didático e da infraestrutura física, como, por exemplo:

As decisões do gasto da verba do PDDE dependem do Conselho de Escola, e isso facilita o trabalho e a autogestão da execução do plano administrativo. (P49).

A escola pode, com esta pequena verba, decidir o que fará com o dinheiro, e essas necessidades conversam mais com a realidade da escola. As vezes recebemos, já comprados da Secretaria, alguns materiais até um pouco 'estranhos'às nossas necessidades. Com o dinheiro do PDDE podemos refletir melhor sobre os rumos do dinheiro. (P18).

$\mathrm{O}$ PDDE, mesmo proporcionando à escola um grau bastante reduzido de autonomia na gestão de recursos financeiros, é avaliado como positivo pelas diretoras, já que permite a aquisição de alguns materiais de uso didático ou administrativo de forma a que elas não fiquem reféns de amarras burocráticas. Isso revela uma aceitação, por parte das diretoras, de alguns elementos mais próprios da forma gerencial de gestão, como a flexibilidade, a eficiência e a desregulamentação. Tais elementos afastam-se da forma burocrática, na qual a gestão financeira se dá de modo centralizado e com grau bem mais reduzido de autonomia.

Quanto ao PPP, os dados revelam que as unidades escolares o elaboram e o atualizam periodicamente. Com relação a quem participa de sua elaboração, indicam participação concentrada principalmente nas figuras da diretora e da coordenadora pedagógica. Isso também se revela quanto a quem se responsabiliza pela garantia da execução do PPP, sendo que, neste caso, há uma concentração ainda maior na figura da diretora. Chamam atenção 
os dados referentes à participação docente, apontada por um número reduzido de diretoras no tocante à elaboração e, menor ainda, quando se considera a responsabilidade pela garantia de execução.

As diretoras foram também instadas a classificar a participação dos diferentes segmentos quanto a sua intensidade. Diretoras, coordenadoras pedagógicas e professoras aparecem com indicações de maior intensidade quando comparadas a outros segmentos. Embora a presença dos professores não seja grande na elaboração e execução do PPP, a intensidade de sua participação é equiparada à das diretoras e coordenadoras, mostrando que quando participam o fazem de forma ativa, o que pode ser indício de interesse em um envolvimento maior.

Tais análises revelam, ainda, a presença do princípio da hierarquia, mais próprio da forma burocrática de organização da escola. É como se a diretora, estando no topo da hierarquia escolar, fizesse parte de um mecanismo (WEBER, 1991) no qual cumpre tarefas especializadas, determinadas por instâncias superiores na hierarquia. Tal como este autor, uma das diretoras empregou a mesma expressão ao se referir ao cumprimento de suas funções formalmente estabelecidas.

$\mathrm{O}$ caráter hierárquico e formalista identificado nas respostas das diretoras mostra que sua concepção de Projeto se distancia do conceito gramsciano apresentado por Dagnino (2004), que teria um caráter emancipatório, marcado pelo vínculo entre cultura e política.

Com relação à BNCC, a visão positiva da maioria absoluta das diretoras se revela em justificativas como: direcionamento e/ou orientação do trabalho pedagógico da escola; obtenção de igual acesso ao ensino-aprendizagem por todos os estudantes; reforço do trabalho da escola na busca de educação de qualidade; direito de todos à aprendizagem, já que, supostamente, todas as crianças teriam acesso ao mesmo conhecimento; existência de um parâmetro a ser seguido em relação aos componentes curriculares; oportunidade de acompanhamento do desenvolvimento curricular e pedagógico pelas equipes escolares. Esses elementos estão presentes em alguns excertos, como, por exemplo:

Reforça o trabalho da escola na busca por uma educação de qualidade, que é direito de todos, pois a criança deve ter o mesmo conhecimento que qualquer outra de qualquer localidade do país. (P15).

A BNCC é positiva, no sentido de orientar a escola e favorecer aos alunos o acompanhamento da aprendizagem. (P29).

Trará um norte para o trabalho pedagógico. (P35).

[A BNCC é positiva] no sentido de acompanhar e auxiliar, junto à coordenação pedagógica, o planejamento e o desenvolvimento dos materiais pedagógicos. (P45).

Em adição a tais asserções, é possível constatar que as justificativas a favor da BNCC demonstram uma dimensão funcional, no sentido de ajudar a escola a resolver questões práticas como, por exemplo, "fazer e receber transferências de alunos" (P52), ou ainda: "No municipio xxx já se trabalha com uma base comum e isso facilita quando há matrículas e transferências dentro do mesmo município. Se for nacional, facilitará sempre” (P38).

Do conjunto das respostas das diretoras destacam-se, como palavras-chave, parâmetro, orientação, direcionamento, norte, acompanhamento, educação igualitária, educação de qualidade. Tais palavras podem ser organizadas numa certa lógica: a BNCC definiria os rumos das ações pedagógicas da escola, permitiria seu acompanhamento, e o resultado seria a garantia da qualidade da educação para todos. A aplicação da Base, portanto, daria conta de cumprir a dimensão pedagógica que faz parte do trabalho das diretoras, razão pela qual elas a avaliam tão positivamente.

Haveria, assim, uma determinação externa que reduziria a autonomia da escola, colocando-a na condição de simples elo de uma corrente; de mera cadeia de um mecanismo. Desse modo, o conjunto dos dados referente à $\mathrm{BNCC}$ permite analisar a gestão das escolas como mais próxima da forma burocrática.

Sobre as avaliações externas, também se verificou uma visão positiva, justificada por pelo menos quatro razões: diagnóstico de dificuldades nos percursos de ensino e aprendizagem; direcionamento para os pontos de chegada da escola (objetivos e metas); organização do trabalho pedagógico, adaptando o currículo e o planejamento conforme os indicadores produzidos pelas avaliações externas; e estimulação e motivação dos agentes escolares para 
buscarem um ensino de qualidade. Eis as respostas dadas por algumas diretoras:

O Ideb do Ensino Fundamental no nosso município está acima da média nacional (5.8), o que a nosso ver não está dentro do ideal, pois sabemos que ainda há um número considerável de alunos com dificuldades de aprendizagens. Nisso as avaliações nos ajudam a elencar pontos que ainda precisam ser mais trabalhados, onde nossos alunos não conseguiram atingir niveis satisfatórios. Também ajudam a indicar as áreas de evolução no ensino e aprendizagem e como caminhar para mantê-las. (P51).

Possibilitam uma reavaliação da prática da docência, bem como o planejamento de ações com vista à melhoria. (P14).

Norteiam as ações gestoras e docentes para o alcance dos resultados educacionais e aprendizagem dos alunos. (P29).

Podemos adaptar o currículo, o planejamento, nos direcionando às dificuldades apresentadas a fim de saná-las. (P59).

A utilização dos resultados das avaliações externas para fins de diagnóstico das dificuldades de aprendizagem dos alunos; de direcionamento e organização do trabalho pedagógico; e de adaptação curricular pode ser entendida na mesma direção do que indicam os dados referentes à $\mathrm{BNCC}$, ou seja, a escola aparece como determinada por forças exógenas, restando-lhe pouca autonomia.

Evidencia-se, com isso, uma estreita relação entre BNCC e Avaliações Externas, na qual a primeira dá a direção pedagógica e curricular e a segunda exerce o papel de regulação das ações das escolas para que atinjam os pontos de chegada previamente estabelecidos pela BNCC.

\subsection{Relações escola-comunidade}

Nesta seção as relações escola-comunidade são abordadas no que se refere às famílias e à comunidade de entorno.

Quanto às relações entre a escola e as famílias, todas as diretoras indicam que elas existem, e de forma intensa. Estariam relacionadas a aspectos pedagógicos, visando à aprendizagem dos alunos, como se pode perceber em respostas como a de P14: "Com a participação da família nas decisões da escola, sinto que as responsabilidades são compartilhadas, evitando uma sobrecarga para a gestão e minimizando os problemas de aprendizagem dos alunos" (P14).

Além disso, essas relações possibilitariam melhor conhecimento da realidade dos estudantes e das expectativas das famílias com relação ao trabalho escolar: "A partir do contato com os pais, eu ficava sabendo das necessidades da comunidade escolar e do entorno. Desse modo, procurava adequar a organização da escola a essas necessidades, sempre que possivel". (P45).

Dessa forma, a confiança das famílias na escola melhoraria, e estas passariam a colaborar com a escola:

O fato de interagir com as familias as torna mais confiantes no trabalho da escola, porque entendem que a escola não está julgando sua cultura e tentando se impor. O fato de haver essa interação faz com que todos se sintam próximos e responsáveis pelo sucesso. (P53).

Outros aspectos alegados pelas diretoras quanto às relações escola-família - todos eles de caráter positivo - são: a troca de experiências, a corresponsabilidade na tomada de decisões, "ajuda" na gestão de conflitos e na articulação da direção com segmentos como Conselho Escolar e APM. Eis como se manifestam algumas delas:

É gratificante a troca de experiências, e a divisão de responsabilidades é sempre um aprendizado para ambas as partes. (P14).

Quando ouvimos a comunidade, partilhamos as responsabilidades, estabelecemos o diálogo e a corresponsabilidade. (P16).

$A$ articulação da comunidade na escola interfere de maneira positiva, pois tem melhorado bastante, e isso ajuda muito o trabalho do gestor, principalmente a gerenciar os conflitos, bem como encontrar soluções. (P54).

Interfere de maneira positiva, fazendo articulação com segmentos (APM e Conselho). (P28).

Tudo isso redundaria no aumento da eficiência do trabalho escolar, já que as famílias facilitariam o trabalho das diretoras. Haveria, ainda, na visão delas, uma "desmistificação" de sua autoridade como incontestável e centralizadora. Essa ideia 
fica explícita, por exemplo, nas seguintes respostas:

O diretor é o grande articulador de todo esse mecanismo, ele deve estar sempre estudando e, mesmo achando que sempre é preciso melhorar, não pode desistir, pois essa articulação deve ser alimentada constantemente. Dessa forma a atuação do diretor se torna mais próxima de todos, desmistificando essa autoridade incontestável e centralizadora, tornando- a acessivel, real e pertencente a um núcleo que atua de forma igualitária. (P24).

Interfere muito porque com o apoio da família as coisas se resolvem mais rapidamente. (P65).

Na relação escola-famílias parecem estar presentes as formas de gestão gerencial e burocrática, com predomínio da primeira, já que os dados revelam a presença da eficiência como elemento importante, porém com conotação diferente da expressa pela burocracia. Nesta, a eficiência tem a ver com a adequação da escola a fatores exógenos, ou seja, quanto mais fiel às regras estabelecidas externamente, mais ajustada e eficiente. $\mathrm{Na}$ forma gerencial a eficiência depende da "ajuda" da comunidade; da partilha de responsabilidades; e da "colaboração" com a escola, elementos fundamentais para fazê-la funcionar. No entanto, tudo isso não se encontra estabelecido normativamente (a exemplo do que ocorre nas relações escola-Estado analisadas neste artigo), mas necessita de uma espécie de "conquista" da confiança das famílias para obtenção de parceria voltada a atender às demandas do Estado. Para tanto, as diretoras não querem ser vistas como tendo uma autoridade "incontestável e centralizadora"; só que, no limite, a "ajuda" e a "parceria" das famílias não estariam voltadas à construção de um projeto emancipatório, mas à eficiência na implementação do "projeto" definido pelo "mecanismo" desde o alto do sistema.

Chama atenção a ênfase atribuída pelas diretoras aos aspectos pedagógicos, no sentido de que a participação dos pais na escola contribuiria para a aprendizagem dos alunos. Convém lembrar, no entanto, a relação exógena da escola com o sistema quando se trata desses aspectos, ou seja, de obediência às definições dadas pelas políticas e determinações legais. Acrescente-se que, pelo conjunto dessas análises, observa-se a relação escola-famílias ocorrendo numa direção de mão única, ou seja, a escola pedindo a colaboração dos pais, a fim de se ajustar às imposições hierárquicas.

Já no tocante às relações entre escola e comunidade de entorno, elas são vistas como de intensidade menor, se comparadas com as relações escola-famílias.

Diferentemente dessas últimas, em que prevalece a justificativa pedagógica, na primeira destaca-se a alusão à parte física da escola (uso do espaço para festas e outros eventos, por parte da comunidade de entorno), bem como à manutenção predial e patrimonial. As respostas P23 e P39 servem de exemplo:

A escola tem procurado ampliar a articulação com a comunidade e com o entorno da escola. Como exemplo disso, indicamos que uma vez ao mês o prédio da escola é cedido para uma associação de moradores realizar suas reuniões. (P23).

Interfere de forma positiva devido a facilitar as conquistas materiais. (P39).

É feita, ainda, alusão à ajuda da comunidade na resolução de conflitos e ao respaldo na tomada de decisões, o que resultaria em "sensação de conforto" por parte da equipe gestora, já que o conjunto desses fatores resultaria em maior rapidez e eficiência nas suas ações.

A articulação da comunidade na escola interfere de maneira positiva, pois tem melhorado bastante, e isso ajuda muito o trabalho do gestor, principalmente a gerenciar os conflitos, bem como encontrar soluções. (P18).

A escola aberta representa oportunidades de escuta e isso me dá conforto para as decisões tomadas. (P51).

Enquanto a demanda da escola em relação à comunidade assume caráter de pedido de auxílio para a realização de suas tarefas, a comunidade demanda da escola, predominantemente, o uso de seu espaço físico, como forma de suprir a ausência de espaços comunitários no bairro, tais como praças, centros, locais de lazer, a exemplo do que enuncia P40 em sua resposta.

O bairro não é antigo, está se formando há uns sete anos; não há centro comunitário, praças, local de lazer. Temos uma grande quantidade de igrejas de diversas religiões, e a escola cede espaço para essas entidades fazerem seu trabalho semanalmente. Interfere diretamente no meu trabalho, pois garanto 
parceiros que colaboram no zelo e nas atividades como voluntariado, propagando para o bairro que a escola também é colaboradora. (P40).

Cabe assinalar, por fim, que os dados não apontam apenas aspectos positivos nas relações escola-comunidade, já que elas representariam uma carga adicional no trabalho das diretoras, "atravancando-o" - para usar a expressão de uma delas - e atrapalhando o desempenho de suas funções essenciais. P18 explicita assim essa ideia: "Toma bastante tempo também, e isso às vezes atravanca um pouco o trabalho, muito em relação à burocracia, que não pode ser deixada de lado, como pagamento dos funcionários, organização das faltas, gestão administrativa da unidade".

Tal qual foi revelado quando analisamos as relações escola-famílias, nas relações escola-comunidade de entorno a ideia de eficiência se coloca na acepção anterior, com destaque para o respaldo à escola em processos de tomada de decisões, o que geraria "conforto" às diretoras. Por outro lado, três aspectos importantes se diferenciam: não alusão a aspectos pedagógicos; relação de mão dupla; reconhecimento das diretoras de um lado negativo dessas relações, expresso pelo trabalho adicional que elas exigem.

No lugar dos aspectos pedagógicos, as relações escola-comunidade de entorno passam fundamentalmente pelo espaço físico, predominando o uso das dependências da escola pela comunidade para a realização de eventos diversos; em troca, a comunidade ofereceria serviços de manutenção predial e patrimonial.

Quanto ao fato de as diretoras perceberem a participação de famílias e comunidade como um trabalho "a mais", o dado revela que as relações da escola com a comunidade de entorno não são vistas como algo essencial; portanto, elas o realizariam na medida das possibilidades.

Ao que se vê, a forma gerencial predomina, em relação à forma burocrática, uma vez que as diretoras reconhecem a necessidade de participação da comunidade, ainda que seja para atingir os objetivos pré-estabelecidos pelo sistema. Nesse caso, o caráter mais ativo da ação das diretoras se faz necessário para colocá-las num lugar de "conforto" que a burocracia, por outros meios, também o faz.

\section{Considerações finais}

Este artigo pretendeu compreender as formas de gestão que vêm se configurando nas escolas, com foco nas relações entre escola-Estado e escola-comunidade. Considerou a existência teórica de três formas de gestão: a burocrática, a gerencial e a emancipatória. Tal opção levou em conta alguns momentos, aqui considerados cruciais, de debate em torno da escola e de sua gestão.

O primeiro desses momentos tem a ver com os esforços de modernização da escola pública nos anos 1950, quando começa a se intensificar o processo de industrialização e, consequentemente, de urbanização, demandando a expansão da escolarização. Nesse contexto, o modelo burocrático representava a forma de modernização da escola como enfrentamento do clientelismo e do patrimonialismo, típicos de uma sociedade considerada arcaica. A obra de Luiz Pereira (1967), A escola numa área metropolitana, por exemplo, expressa bem o esforço analítico de compreensão da escola e de teorização da sua gestão que, até essa época, era mais orientada para aspectos normativos, de caráter prescritivo, pautada em conhecimentos de ordem prática (OPLATKA, 2016).

O segundo momento de debate acerca da escola e da sua gestão se caracteriza por duas vertentes, uma de caráter emancipatório e outra gerencialista. A emancipatória tem início no final dos anos 1970 , no seio do processo interno de redemocratização do país face aos anos de ditadura civil-militar, buscando "implementar um projeto de construção democrática, de transformação social" (DAGNINO, 2004, p. 153). A gerencialista ganha destaque nos anos 1990, no interior do processo de globalização, de cunho neoliberal, período no qual se considerava que a "grande tarefa política" seria superar o suposto "gigantismo burocrático" do Estado (BRASIL, 1995, p. 16), marcado pelo combate à burocracia, do que se depreende que esta, além de não superar os traços patrimonialistas e clientelistas, tornou-se, ela mesma, um problema a ser enfrentado.

O princípio básico da eficiência é comum às três formas de gestão, com ênfases e sentidos distintos, como evidenciou a análise dos dados da pesquisa. 
$\mathrm{Na}$ forma burocrática, a eficiência expressa a qualidade de resposta da escola para se adequar a fatores exógenos, em fidelidade às regras vindas de cima. Na forma gerencial ela requer algum nível de participação das famílias e da comunidade de entorno da escola para se atingir os resultados esperados por esta, em consonância com as políticas públicas e as normativas legais. Na forma de gestão emancipatória, por sua vez, a eficiência também prevê a participação, porém neste caso não entendida como recurso gerencial, mas envolvendo os participantes na tomada de decisões coerentes com o projeto democratizante, marcado pelo vínculo indissolúvel entre a cultura e a política (CEVASCO, 2003; DAGNINO, 2004) e que implica uma cosmovisão democrática (TORO, 2007).

Os resultados da pesquisa mostraram, na análise das relações escola-Estado, o predomínio da forma burocrática, podendo relacionar-se ao conceito de autonomia decretada (BARROSO, 1996), ou seja, à definição das margens de liberdade de ação das unidades escolares pelo conjunto de normas estabelecido por órgãos superiores responsáveis pela administração da educação.

Quanto à análise dos resultados referentes às relações escola-comunidade, embora tenham envolvido a participação das famílias e da comunidade de entorno, ela parece ter assumido um caráter de recurso gerencial (NOGUEIRA, 2011), no sentido de solidarizar governantes e governados, reduzindo atritos entre ambos.
O conjunto dos resultados da pesquisa revela que a forma burocrática de gestão das escolas continua vigorosa, principalmente no que se refere a alguns de seus princípios fundamentais, como é o caso do verticalismo das decisões e da hierarquia. Ao mesmo tempo, foi verificada a presença de traços gerencialistas, revelando-se, assim, uma área de interseção entre os fortes princípios da burocracia e os fracos princípios do gerencialismo. Os princípios da forma emancipatória de gestão não se revelaram explicitamente nos dados, ainda que se possa admitir, com Nogueira (2011), que a presença da participação, na forma gerencial, possa constituir um germe da forma emancipatória.

Dessa forma, vê-se um tipo de racionalidade que atravessa as relações da escola de uma ponta a outra, isto é, a escola servindo ao Estado e a comunidade servindo à escola, com vista à eficiência e eficácia do trabalho escolar.

Assim, a democratização da gestão educacional - princípio constitucional - vai assumindo um caráter de racionalidade técnica e eficácia econômica (AZEVEDO, 2009), não alcançando a forma de gestão emancipatória, que envolveria também os conceitos de efetividade e relevância (SANDER, 2007). Corresponderia também à autonomia na tomada de decisões pelas escolas em diferentes domínios, por meio de ação organizada e em razão de objetivos coletivos próprios, ao que Barroso (1996) entende como autonomia construída.

\section{REFERÊNCIAS}

AZEVEDO, J. M. L. Programas federais para a gestão da educação básica: continuidade e mudanças. Revista Brasileira de Política e Administração da Educação, Porto Alegre, v. 25, n. 2, p. 211-231, maio/ago. 2009.

BARROSO, J. O estudo da autonomia da escola: da autonomia decretada à autonomia construída. In: $\mathbf{O}$ estudo da escola. Porto, PT: Porto Editora, 1996.

BRASIL. Presidência da República. Casa Civil. Constituição da República Federativa do Brasil de 1988. Brasília, DF, 1988. Disponível em: <http://www.planalto.gov.br/ccivil_03/constituicao/constituicaocompilado.htm>. Acesso em: 30 set. 2018.

Ministério da Administração Federal e Reforma do Estado. Câmara da Reforma do Estado. Plano diretor da reforma do aparelho do Estado. Brasília, DF, 1995. Disponível em: <http://www.bresserpereira.org.br/documents/mare/planodiretor>. Acesso em: 4 out. 2018.

CEVASCO, M. E. Dez lições sobre estudos culturais. São Paulo: Boitempo, 2003.

DAGNINO, E. Construção democrática, neoliberalismo e participação: os dilemas da confluência perversa. Política 
\& Sociedade, Florianópolis, SC, n. 5, p. 139-164, out. 2004. Disponível em: <https://periodicos.ufsc.br/index.php/ politica/article/viewFile/\%201983/1732>. Acesso em: 18 ago. 2018.

NOGUEIRA, M. A. Um estado para a sociedade civil: temas éticos e políticos da gestão democrática. 3. ed. São Paulo: Cortez, 2011.

OPLATKA, I. El surgimiento de la gestión educativa como campo de estudio en América Latina In: WEINSTEIN, J. (Ed.). Liderazgo educativo en la escuela: nueve miradas. Santiago de Chile: Ediciones Universidad Diego Portales, 2016. p. 253-276.

PEREIRA, Luiz. A escola numa área metropolitana. São Paulo: Livraria Pioneira/Editora da Universidade de São Paulo, 1967.

SANDER, B. Administração da Educação no Brasil: genealogia do conhecimento. Brasília, DF: Liber Livro, 2007.

TORO, J. B. Educación para la democracia. 2007. Disponível em: <http://funredes.org/funredes/html/castellano/ publicaciones/educdemo.html>. Acesso em: 27 out. 2018.

WEBER, M. O que é a burocracia. Brasília, DF: Conselho Federal de Administração, 1991.

Recebido em: 30/07/2018

Aprovado em: 22/10/2018 